\section{Weight-teasing: does body dissatisfaction mediate weight-control behaviors of Brazilian adolescent girls from low-income communities?}

Provocações em relação ao peso corporal: a insatisfação com o próprio corpo afeta o comportamento de controle de peso de adolescentes brasileiras de comunidades de baixa renda?

Burlas y acoso por el peso: ¿la insatisfacción corporal afecta al comportamiento para el control del peso en adolescentes brasileñas dentro de comunidades con baja renta?

\begin{abstract}
The objective was to examine the mediation hypothesis of body dissatisfaction and analyze their association with weight-teasing and body satisfaction. A total of 253 girls who attended 10 schools from São Paulo, Brazil, participated in this study. Data collection was carried out through a validated and selfreported questionnaire. Study variables were weight-teasing (independent), body satisfaction (mediation), and weight control behavior (outcome). Effect mediation analyses showed a significance level of 5\% $(p<0.05)$. Prevalence of family and peers weight-teasing were $38.5 \%$ and $40.6 \%$, respectively. Body dissatisfaction was associated with unhealthy weight control behaviors when controlled by family and peer weight-teasing. Data indicate that family and peers teasing are important aspects that interfere in body satisfaction and weight control behaviors.
\end{abstract}

Feeding Behavior; Adolescent Behavior; Peer Influence; Family
Sonia Tucunduva Philippi 1

Ana Carolina Barco Leme 1

doi: 10.1590/0102-311X00029817

\author{
Correspondence \\ A. C. B. Leme \\ Faculdade de Saúde Pública, Universidade de São Paulo. \\ Av. Dr. Arnaldo 715, São Paulo, SP 01255-000, Brasil. \\ acarol.leme@gmail.com \\ 1 Faculdade de Saúde Pública, Universidade de São Paulo, São \\ Paulo, Brasil.
}




\section{Introduction}

Adolescence is a development period in which occurs significant psychological and physical changes in body composition 1. It is during this period that we note an increased concern with their body image, especially among female adolescents, which triggers them to compare themselves to others regarding body appearance and function. Evidence suggests that this concern is probably influenced by the social concepts of attractiveness, generally typified by a slim body. Young people that present bodies that do not align with this ideal, i.e., big in size, fat or overweight, are frequently weight-teased and seem as not healthy, attractive and desirable 2 . The "cultural appearance" is, therefore, an important aspect to consider when it comes to adolescents, where physical attractiveness is the main focus of attention, comparison, and social assessment 3 .

Adolescent teasing is frequent and it is used to communicate violation to social appearance norms, thus the fact of body weight being a common focus of teasing is not a surprise ${ }^{3}$. Regarding weight or body shape teasing, harassment or comments constitute a specific form of bullying, which is particularly relevant when addressing body dissatisfaction and weight control behaviors in adolescents 4 . Appearance responses in the form of mocking, humiliating and using nicknames, such as "fatty", "chubby", "jelly fat", among others, are frequent ways of verbal teasing 5,6. These comments might come from the family (e.g., siblings, cousins and parents), peers, friends, and romantic partners 7 .

Weight-teasing, independently of the source, can be associated with an increasing body image dissatisfaction, leading to unhealthy weight behaviors, such as restrictive diets, use of (partial) meal replacements, and fasting 8,9 .

Some researchers have been studying the empirical association between weight-teasing, body dissatisfaction, and weight control behaviors 3,4,9, but there is still a lack of studies that aim suggest and test conception models, understanding the theory that represents the proposed path to identify possible mechanisms under investigation, including the mediators that lead to teasing, weight control behaviors, and effects in body dissatisfaction.

The mediator variable (body satisfaction) was situated between an independent variable (weightteasing) and a dependent variable (weight control behaviors) in a casual chain 10 . However, the best evidence is to isolate the causal effects of being or not being weight teased by identifying the body satisfaction mediators, providing useful information for future surveillance and intervention studies, also suggesting the behaviors that should be emphasized and the ones that should be removed for being less important. Therefore, the aim of this study was to examine the mediator hypothesis of body dissatisfaction and analyze their association between weight-teasing and weight control behavior in Brazilian adolescents.

\section{Methods}

\section{Study design}

This study is a secondary analysis of baseline data collected in 2014, as part of a school-based randomized controlled trial called Healthy Eating, Healthy Girls - Brazil (H3G-Brazil) 11,12. The H3G-Brazil was a 6-month obesity prevention program for girls from low-income communities, whose protocol and methods are published elsewhere 12 .

\section{Participants}

The inclusion criteria were adolescent girls from 14 to 18 years of age enrolled in public technical schools of the city of São Paulo, Brazil. The exclusion criteria were adolescent boys and participants enrolled in the nutrition technical course or other health-related technical courses.

Participants were recruited from 10 technical public schools located in different areas of the city of São Paulo. Technical schools that have nutrition and dietetic courses were selected ( $\mathrm{n}=13)$ because of a partnership made with the teachers and coordinators of these schools. Despite selecting schools that have nutrition and dietetics courses, the adolescents selected were not enrolled in neither of 
them. Therefore, they were attending regular high school during the morning and the following technical courses such as building trades, business and management, chemistry, environmental sciences, and visual communication in the afternoon. From the 13 schools that have the nutrition and dietetics courses, only 10 participated in the study (i.e., one refused to participate and two did not meet eligibility criteria). Considering each class had approximately 30 students from both sexes, thus we selected approximately 25 girls from each school to reach the calculated sample size (i.e., $\mathrm{N}=253$ ). Written assent and consent forms were signed by the school directors, parents/caregivers, and the adolescents. The Institutional Review Board from the University of São Paulo approved the study.

\section{Data collection}

Trained research assistants conducted the data collection in blind. Moreover, they followed a manual protocol with specific instructions for the conduction of all the assessments. Physical assessments were conducted in a sensitive way (i.e., weight measured out of the views of other students) and questionnaires were completed after the physical evaluations under exam-like conditions.

\section{Variables}

Physical measurements were conducted in a sensitive way; the weight was measured individually. The questionnaires were filled after obtaining physical measurements in exam-like conditions.

Questions referred to weight-teasing, body satisfaction, weight control behavior and weight-teasing by family members and peers were assessed using a previous adapted and validated questionnaire with adolescents from the city of São Paulo 9.

Body satisfaction was assessed through the Likert scale of 7 points (very dissatisfied to very satisfied) for height, weight, body shape, waist, hips, thighs, stomach, face, arms, and shoulders $(\alpha=0.88)$.

Weight control behaviors were reported by adolescents through yes and no answers. A total of 16 weight reduction and maintenance strategies were verified in the previous 12 months. The items were compiled in two scales, using the Cronbach's alpha coefficient for healthy weight behaviors and unhealthy weight behaviors.

Healthy weight control behaviors included the following items: practice of regular physical activity; decrease of food consumption; ingestion of more fruits and vegetables; reduced intake of food rich in trans and saturated fat; reduction of soft-drinks and other sugar-sweetened beverages intake (i.e., nectar and powder juices); attention to portion size; and decrease of sweets and treats consumption. This scale showed a reproducibility coefficient of $\alpha=0.68$.

Unhealthy weight behaviors were: fasting; pills; vomit induction; laxatives use; diuretic use; (partial) meals replacement; smoking; and restrictive diet. This scale showed an acceptable reproducibility $(\alpha=0.54)$.

\section{Data analysis}

Data were analyzed with the IBM SPSS software (version 21.0; IBM Corp., Armonk, USA), using PROCESS Macro (version 21.6; http://www.processmacro.org/index.html) 13. Descriptive analyses were conducted using mean and standard error for continuous variables, and frequency and percentages for categorical variables.

PROCESS calculated the path of the A and B coefficients, the direct effect of C', and simultaneously significant mediator effects (AB). Figure 1 shows the paths and coefficients tested. The path A involved the potential regression of mediators in weight-teasing conditions. The direct effect of teasing in the outcomes of weight control behaviors was estimated through the regression of teasing behaviors ( $C^{\prime}$ coefficient). The model also provided the association between potential mediators (coefficient B) with behavioral outcomes. Thus, the significance of coefficient-products (AB) was determined using asymmetric bootstrap bias correction with confidence interval (CI). For the mediator effects to be considered statistically significant, the 95\%CI should not include zero. Alpha levels were established at 0.05 for all analyses. 
Hypothesized pathways and the coefficient included in the single mediator model.

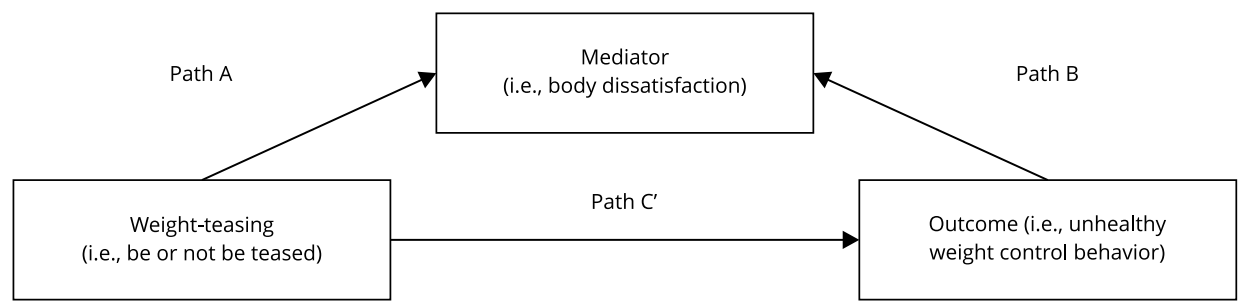

\section{Results}

A total of 253 female adolescents (mean age $=15.62$ years, standard error $=0.05$ ) of 10 public schools from the city of São Paulo, participated in the study. Girls reported that $38.5 \%$ of their family members and $40.6 \%$ of their peers weight-teased them in the previous year. Regarding family teasing, the highest prevalence was came from siblings (55.7\%), mothers (40.9\%) and fathers (18.2\%). Among unhealthy weight behaviors, the most reported ones were: skipping meals (32.1\%), restrictive diets (17.9\%) and fasting (17.1\%). And for the healthy weight control behaviors, the ones mostly mentioned were: ingestion of more fruits and vegetables (65.4\%), attention portion sizes (53.8\%), and practice of regular physical activity (51.3\%). In general, the average of body satisfaction for the girls was 4.3 (standard error $=0.08$ ) (scale varying from 1 very dissatisfied to 7 very satisfied). The items that adolescents reported the highest dissatisfaction were stomach (63.7\%) and weight (62.4\%), and the items with the highest satisfaction were face (63.3\%) and shoulders (60.7\%) (data not shown).

\section{Path A (weight-teasing vs. body image satisfaction)}

Weight-teasing by family members demonstrated statistical difference for all the items that assessed body dissatisfaction. On the other hand, being weight-teased by peers was associated with weight $(ß=0.37, \mathrm{p}<0.05)$, body shape $(\beta=-0.73, \mathrm{p}<0.01)$, hips $(B=0.60, \mathrm{p}<0.01)$, thighs $(\Omega=0.83, \mathrm{p}<0.01)$, face $(\beta=0.67, \mathrm{p}<0.01)$, arms $(\beta=0.50, \mathrm{p}<0.05)$ and shoulders $(\beta=0.52, \mathrm{p}<0.01)$ (Tables 1 and 2$)$.

\section{Path B (body satisfaction vs. weight control behaviors)}

When considering family weight-teasing, the weight control behaviors were mostly associated with body dissatisfaction, with just one exception for height, thighs, face, and shoulders. When considering weight-teasing by peers, there was a statistical significant difference for all the items associated with weight control behaviors, with one exception for height (Tables 1 and 2).

\section{Mediator effects}

Family weight-teasing and unhealthy weight control behaviors were mediated by weight $(\Omega=0.02$, 95\%CI: 0.01; 0.03), body shape ( $(=0.03$, 95\%CI: 0.01; 0.05), waist ( $(=0.01,95 \% \mathrm{CI}: 0.01$; 0.02), hips $(ß=0.01,95 \% \mathrm{CI}: 0.01 ; 0.02)$, stomach $(ß=0.02$, 95\%CI: $0.01 ; 0.04)$ and arms $(ß=0.01,95 \% \mathrm{CI}: 0.01$; 0.02). The variables that mediated the effect of peer weight-teasing and unhealthy weight control behaviors were weight ( $(=0.01,95 \% \mathrm{CI}: 0.01$; 0.03), body shape ( $\beta=0.02,95 \% \mathrm{CI}$ : 0.01 ; 0.04$)$, hips $(\beta=0.01,95 \% \mathrm{CI}: 0.01 ; 0.03)$, thighs $(\beta=0.01,95 \% \mathrm{CI}: 0.01 ; 0.02)$, face $(\beta=0.01,95 \% \mathrm{CI}: 0.01 ; 0.02)$, arms ( $(=0.01,95 \% \mathrm{CI}: 0.01 ; 0.02)$ and shoulders $(\beta=0.01,95 \% \mathrm{CI}: 0.01 ; 0.02)$ (Tables 1 and 2$)$. 
Table 1

Results of mediation effects in family weight-teasing prior to baseline, and associations between body image satisfaction and weight control behaviors.

\begin{tabular}{|c|c|c|c|c|c|}
\hline Hypothesized mediator * & $C^{\prime}(\mathrm{SE})$ & $A(S E)$ & B (SE) & $\mathrm{AB}(95 \% \mathrm{Cl})$ & Total effect ** \\
\hline Height satisfaction & $0.08(0.01) * * *$ & $0.50(0.23) \#$ & $-0.01(0.01)$ & $-0.01(-0.01 ; 0.02)$ & $0.08(0.01) * * *$ \\
\hline Weight satisfaction & $0.05(0.01) * * *$ & $0.95(0.22) * * *$ & $0.02(0.01) * * *$ & $0.02(0.01 ; 0.03)$ & $0.08(0.01) * * *$ \\
\hline Body shape satisfaction & $0.04(0.01) * * *$ & $1.02(0.22) * * *$ & $0.03(0.01) * * *$ & $0.03(0.01 ; 0.05)$ & $0.08(0.01) * * *$ \\
\hline Waist satisfaction & $0.06(0.01) * * *$ & $0.77(0.21) * \star *$ & $0.01(0.01) * * \star$ & $0.01(0.01 ; 0.02)$ & $0.08(0.01) * * *$ \\
\hline Hips satisfaction & $0.06(0.01) * * *$ & $0.77(0.21) * \star \star$ & $0.02(0.01) * \star \star *$ & $0.01(0.01 ; 0.02)$ & $0.08(0.01) * * *$ \\
\hline Thighs satisfaction & $0.07(0.01) * * *$ & $0.66(0.22) * \star \star$ & $0.01(0.01)$ & $0.01(-0.01 ; 0.01)$ & $0.08(0.01) * * *$ \\
\hline Stomach satisfaction & $0.05(0.01) * * *$ & $0.78(0.24) * \star \star$ & $0.02(0.00) * \star \star$ & $0.02(0.01 ; 0.04)$ & $0.08(0.01) * * \star$ \\
\hline Face satisfaction & $0.07(0.01) * * \star$ & $0.74(0.21) * \star \star$ & $0.01(0.01)$ & $0.01(-0.01 ; 0.02)$ & $0.08(0.01) * * *$ \\
\hline Arms satisfaction & $0.06(0.01) * * *$ & $0.92(0.23) * * *$ & $0.01(0.01) * * *$ & $0.01(0.01 ; 0.02)$ & $0.08(0.01) * * *$ \\
\hline Shoulders satisfaction & $0.07(0.01) * * *$ & $0.90(0.20) * * *$ & $0.01(0.01)$ & $0.01(-0.01 ; 0.02)$ & $0.08(0.01) * * *$ \\
\hline
\end{tabular}

95\%Cl: 95\% confidence interval; A: weight-teasing effect on mediators; AB: indirect or "mediated" effect (product of coefficients estimates);

B: association between mediators and unhealthy weight control behaviors; $C^{\prime}$ : direct effect of weight-teasing on unhealthy weight control behaviors;

SE: standard error.

* Mediators presented regarding magnitude of unique mediated effected on unhealthy weight control behaviors;

** Unique proportion of weight-teasing effect on mediated unhealthy weight control behaviors (calculated from non-rounded results);

$* \star * p<0.01$;

$\# p<0.05$.

\section{Table 2}

Results of mediation effects in friends weight-related teasing prior to baseline, and associations between body image satisfaction and weight control behaviors.

\begin{tabular}{|c|c|c|c|c|c|}
\hline Hypothesized mediator * & $C^{\prime}$ (SE) & A (SE) & B (SE) & $\mathrm{AB}(95 \% \mathrm{CI})$ & Total effect ** \\
\hline Height satisfaction & $-0.01(0.01)$ & $0.37(0.23)$ & $-0.01(0.01)$ & $-0.01(-0.01 ; 0.01)$ & $-0.01(0.01)$ \\
\hline Weight satisfaction & $-0.01(0.01)$ & $0.60(0.23) * \star *$ & $0.02(0.01) \#$ & $0.01(0.01 ; 0.03)$ & $-0.01(0.01)$ \\
\hline Body shape satisfaction & $-0.02(0.01)$ & $0.73(0.22) \#$ & $0.02(0.01) \#$ & $0.02(0.01 ; 0.04)$ & $-0.01(0.01)$ \\
\hline Waist satisfaction & $-0.01(0.01)$ & $0.25(0.23)$ & $0.03(0.01) \#$ & $0.01(-0.01 ; 0.02)$ & $-0.01(0.01)$ \\
\hline Hips satisfaction & $-0.01(0.01)$ & $0.60(0.21) \#$ & 0.02 (0.01) \# & $0.01(0.01 ; 0.03)$ & $-0.01(0.01)$ \\
\hline Thighs satisfaction & $-0.01(0.01)$ & $0.83(0.22) \#$ & $0.01(0.01) * \star *$ & $0.01(0.01 ; 0.02)$ & $-0.01(0.01)$ \\
\hline Stomach satisfaction & $-0.01(0.01)$ & $0.20(0.25)$ & $0.03(0.01)$ \# & $0.01(-0.01 ; 0.02)$ & $-0.01(0.01)$ \\
\hline Face satisfaction & $-0.01(0.01)$ & $0.67(0.20)$ \# & $0.01(0.01) \#$ & $0.01(0.01 ; 0.02)$ & $-0.01(0.01)$ \\
\hline Arms satisfaction & $-0.01(0.01)$ & $0.50(0.23) * * *$ & $0.02(0.01) \#$ & $0.01(0.01 ; 0.02)$ & $-0.01(0.01)$ \\
\hline Shoulders satisfaction & $-0.01(0.01)$ & $0.52(0.21) * * *$ & $0.01(0.01) \#$ & $0.01(0.01 ; 0.02)$ & $-0.01(0.01)$ \\
\hline
\end{tabular}

95\%Cl: 95\% confidence interval; A: weight-teasing effect on mediators; AB: indirect or "mediated" effect (product of coefficients estimates); B: association between mediators and unhealthy weight control behaviors; C': direct effect of weight-teasing on unhealthy weight control behaviors;

SE: standard error.

* Mediators presented regarding magnitude of unique mediated effected on unhealthy weight control behaviors;

** Unique proportion of weight-teasing effect on mediated unhealthy weight control behaviors (calculated from non-rounded results);

$\star * \star p<0.05$;

$\# p<0.01$.

\section{Discussion}

Previous research has identified that weight-teasing is associated with psychological factors, such as body image dissatisfaction and weight control behaviors, with an increase of studies conducted internationally 3,4,14,15, but only one conducted in Brazil 9. The study was extended to examine the hypothesis of weight control behaviors mediating body satisfaction, independently of weight-teasing (by family members and peers). 
Consequently, a higher proportion of adolescents reported weight-teasing by both family members and peers. Evidence suggests that appearance teasing is a common phenomenon during adolescence in different cultures 5. For instance, a previous study with adolescents from the Czech Republic demonstrated that more than 33\% of adolescents reported being weight-teased 5. Similarly, a longitudinal study of adolescents from the United States revealed a prevalence of $60.8 \%$ with longterm maintenance 16. Nevertheless, it should be noted that the prevalence of teasing differs from several methodological reasons. According to the study of Almenara \& Jezek 5 , the prevalence can be explained by understanding the effects through a separate question on the different sources of weightteasing (family vs. peers). This approach leads to a more reliable prevalence to investigate epidemiological studies; however, because of the information gap, future researchers are necessary to examine a great extension of variability on the prevalence of weight-teasing/appearance in different cultures. Some of them have been carried out in Brazil on the generalization of bullying and victimization in adolescents 17,18 .

Family and/or peers comments, such as "fat talk", are considered an important weight-teasing 19. The results demonstrated that, independently of the source, teasing is very prevalent, being associated with body dissatisfaction, mainly with weight, body shape, thighs, arms and shoulders, which have consequences to weight control behaviors. The previous review suggests that weight-teasing can lead to binge eating and other eating disorders (purgation and restriction), suggesting that there is a potential for the development to obesity and eating disorders 8 .

Relevant results of family weight-teasing are consistent with the Family System Theory, which sustains the interactions that occur in the family can lead to sustainable interaction patterns, suggesting that teasing can pass from generations to generations, i.e, parents that were teased pass it on to their own kids in some way, either through the concern to maintain a healthy weight, or fat-related comments 19 . Moreover, parental eating disorders symptoms can emerge as a significant predictor to weight and body shape concerns. Adolescents that experience this at home can imitate or internationalize the parents and other family members' attitudes and eating behaviors, increasing weight concern. Furthermore, parents and family members psychological symptoms appeared as important to comprehend the characteristics of adolescents. Family psychological health can be an important factor to comprehend outcome prevention to a healthy weight in youth with weight-related problems ${ }^{14}$.

Given the influence of peers on the ideal internalization regarding appearance during adolescence, we aimed at observing peers weight-teasing mainly in the school environment. This can suggest that internalization ideas of weight and body shape can be related to low self-esteem, depressive symptoms, body dissatisfaction, and the large scale use of weight control behaviors. In this sense, this study found an association between the mediators' hypothesis and the weight control behaviors regarding teasing.

For the adolescents of this study, peers teasing were associated with the level of body appearance satisfaction, resulting in inadequate weight control behaviors. Mocking during physical education classes also can be considered a weight-teasing. Adolescents that report being weight teased perceive themselves as being less physically capable and believe that they were less able to do physical activities. Additional studies are necessary to assess this association and examine if or how the self-physical concept and self-efficacy to adolescents' physical activity can influence physical activity behaviors. The physical education teacher seems to play an important role in weight-teasing 3.

Construct hypothesis to predict body image satisfaction leading to weight control behaviors showed an effect on relative weight-teasing by family and peers 9,20. Showing an increase in the prevalence of weight-teasing, it can be considered a worldwide public health concern. Therefore, it is important to identify groups/individuals that young people can look forward to supporting, and the types of strategies that can help them tackle and prevent teasing. Puhl et al. 21 demonstrates that a higher proportion of adolescents that are weight teased wish that interventions came from others; peers are the most preferred intervention agents followed by classroom teachers, physical education teachers, and parents. Previous weight-teasing experience was reported by most part of the sample and with an increase in teasing frequency participants were more prone to interventions.

This study presented contributes to the literature in this field. The used questionnaires presented acceptable validity and reproducibility. Moreover, the questions referred to weight-teasing verified two different sources: family and peers. 
Some limitations should be noted when interpreting the results. This study is limited forusing cross-sectional data that did not allow us to draw conclusions on the results. Despite being of baseline, data belong to a population of adolescents attending prevention programs whose school community, such as teachers, peers and parents/caregivers, is surrounded by obesity. Finally, because we have only recruited adolescents from public technical schools of the city of São Paulo, the results of this study cannot be generalized to other places. However, this could a useful tool for future national comparisons with on the theme. There is a gap in the national literature that focus on weight-teasing, body satisfaction, and weight control behaviors. This study might provide new insights for future national studies.

\section{Conclusion}

Adolescents from São Paulo that were weight teased by family or peers tend to be more dissatisfied with their physical appearance, which results in unhealthy weight control behaviors. The main concern refers to the use of non-healthy weight practices to attain the beauty ideal proposed by society and emphasized by weight bias and stigma against peers that are overweight. The results have implications for future preventive efforts and still need further study. Preventive activities aiming to decrease weight-teasing might broaden the approach of offensive teasing. Interventions are necessary to ease positive interactions between family and peers and reduce the prejudice regarding appearance. Schools and home are adequate environments for interventions considering adolescents spent most of their time at school and are exposed to different teasing sources, for example, friends and peers, and family. Evidence has suggested that social support from friends and family, and perceived likelihood and helpfulness of intervention significantly influenced participant preferences for certain types of intervention, specifically in the school and home environment 21.

\section{Contributors}

S. T. Philippi participated on study concept and design, acquisition of data, interpretation of data, administrative, and technical and material support and study supervision. A. C. B. Leme participated on study concept and design, acquisition of data, analysis and interpretation of data, drafting the manuscript, critical revision of the manuscript for important intellectual content, statistical analysis and administrative, technical and material support.

\section{Acknowledgments}

The authors would like to thank the girls that participated in the Healthy Habits, Healthy Girls - Brazil study, the schools' coordinators, the nutrition and dietetic teachers from the technical schools, nutrition and dietetics undergraduate students and graduate students from the School of Public Health, University of São Paulo (FSP/USP), Brazil. Moreover, we would like to thank São Paulo State Research Foundation (FAPESP) for the postdoctoral training at the FSP/USP for A. C. B. Leme (process number 2015/20852-7) and A. C. B. Leme grant received from FAPESP (process number 2016/21144-9) for conducting her postdoc training at the Children's Nutrition Research Center, Baylor College of Medicine, Houston, USA. 


\section{References}

1. Hazen E, Schlozman S, Beresin E. Adolescent psychological development: a review. Pediatr Rev 2008; 29:161-7.

2. Haines J, Hannan PJ, van den Berg P, Eisenberg ME, Neumark-Sztainer D. Weight-related teasing from adolescence to young adulthood: longitudinal and secular trends between 1999 and 2010. Obesity (Silver Spring) 2013; 21:E428-34.

3. Greenleaf C, Petrie TA, Martin SB. Relationship of weight-based teasing and adolescents' psychological well-being and physical health. J Sch Health 2014; 84:49-55.

4. Lampard AM, MacLehose RF, Eisenberg ME, Neumark-Sztainer D, Davison KK. Weightrelated teasing in the school environment: associations with psychosocial health and weight control practices among adolescent boys and girls. J Youth Adolesc 2014; 43:1770-80.

5. Almenara CA, Jezek S. The source and impact of appearance teasing: an examination by sex and weight status among early adolescents from the Czech Republic. J Sch Health 2015; 85:163-70.

6. Puhl RM, Peterson JL, Luedicke J. Weightbased victimization: bullying experiences of weight loss treatment-seeking youth. Pediatrics 2013; 131:e1-9.

7. Eisenberg ME, Berge JM, Fulkerson JA, Neumark-Sztainer D. Associations between hurtful weight-related comments by family and significant other and the development of disordered eating behaviors in young adults. $\mathrm{J} \mathrm{Be}-$ hav Med 2012; 35:500-8.

8. Haines J, Neumark-Sztainer D. Prevention of obesity and eating disorders: a consideration of shared risk factors. Health Educ Res 2006; 21:770-82.

9. Leme AC, Philippi ST. Teasing and weightcontrol behaviors in adolescent girls. Rev Paul Pediatr 2013; 31:431-6.

10. Kraemer HC, Stice E, Kazdin A, Offord D, Kupfer D. How do risk factors work together? Mediators, moderators, and independent, overlapping, and proxy risk factors. Am J Psychiatry 2001; 158:848-56.

11. Leme AC, Lubans DR, Guerra PH, Dewar D, Toassa EC, Philippi ST. Preventing obesity among Brazilian adolescent girls: six-month outcomes of the Healthy Habits, Healthy GirlsBrazil school-based randomized controlled trial. Prev Med 2016; 86:77-83.
12. Leme AC, Philippi ST. The "Healthy Habits, Healthy Girls" randomized controlled trial for girls: study design, protocol, and baseline results. Cad Saúde Pública 2015; 31:1381-94.

13. Hayes AF. Introduction to mediation, moderation, and conditional process analysis: a regression-based approach. New York: Guilford Press; 2013.

14. Sinton MM, Goldschmidt AB, Aspen V, Theim KR, Stein RI, Saelens BE, et al. Psychosocial correlates of shape and weight concerns in overweight pre-adolescents. J Youth Adolesc 2012; 41:67-75.

15. Lev-Ari L, Baumgarten-Katz I, Zohar AH. Show me your friends, and I shall show you who you are: the way attachment and social comparisons influence body dissatisfaction. Eur Eat Disord Rev 2014; 22:463-9.

16. Eisenberg ME, Neumark-Sztainer D, Haines J, Wall M. Weight-teasing and emotional well-being in adolescents: longitudinal findings from Project EAT. J Adolesc Health 2006; 38:675-83

17. Malta DC, Porto DL, Crespo CD, Sillva MMA, Andrade SSC, Mello FCM, et al. Bullying in Brazilian school children: analysis of the $\mathrm{Na}$ tional Adolescent School-based Health Survey (PeNSE 2012). Rev Bras Epidemiol 2014; 17 Suppl 1:92-105.

18. Malta DC, Prado RR, Dias AJ, Mello FC, Silva MA, Costa MR, et al. Bullying and associated factors among Brazilian adolescents: analysis of the National Adolescent School-based Health Survey (PeNSE 2012). Rev Bras Epidemiol 2014; 17 Suppl 1:131-45.

19. Eisenberg ME, Berge JM, Fulkerson JA, Neumark-Sztainer D. Weight comments by family and significant others in young adulthood. Body Image 2011; 8:12-9.

20. Bardone-Cone AM, Cass KM, Ford JA. Examining body dissatisfaction in young men within a biopsychosocial framework. Body Image 2008; 5:183-94.

21. Puhl RM, Peterson JL, Luedicke J. Strategies to address weight-based victimization: youths' preferred support interventions from classmates, teachers, and parents. J Youth Adolesc 2013; 42:315-27. 


\section{Resumo}

O estudo teve como objetivo examinar a hipótese da mediação pela insatisfação com o próprio corpo $e$ analisar as associações com a provocação por terceiros e com a satisfação com o corpo. A amostra incluiu um total de 253 adolescentes do sexo feminino matriculadas em dez escolas na cidade de São Paulo, Brasil. Os dados foram coletados com um questionário validado e auto-preenchido. As variáveis de estudo foram as provocações feitas por outros em relação ao peso da adolescente (independente), a satisfação com o corpo (de mediação) e o comportamento de controle do peso (desfecho). As análises de mediação mostraram um efeito estatisticamente significativo $(p<0,05)$. As taxas de prevalência de provocações relacionadas ao peso, feitas por familiares e colegas, foram 38,5\% e 40,6\%, respectivamente. Depois de ajustar para a provocação por familiares e colegas, a insatisfação com o próprio corpo esteve associada a comportamentos prejudiciais de controle de peso. Os dados indicam que as provocações por familiares e colegas são aspectos importantes que interferem na satisfação com o corpo e com os comportamentos de controle de peso.

Comportamento Alimentar; Comportamento do Adolescente; Influência dos Pares; Família

\section{Resumen}

El objetivo fue examinar la mediación en la hipótesis de la insatisfacción corporal y analiza su asociación con las burlas y acoso por el peso y la satisfacción corporal. Un total de 253 niñas que iban a diez escuelas de São Paulo, Brasil, participaron en este estudio. La obtención de datos se llevó a cabo mediante un cuestionario validado y autoinformado. Las variables de estudio fueron acoso por peso (independiente), satisfacción corporal (mediación), y control de peso comportamiento (resultado). El efecto de los análisis de mediación mostró un nivel de significancia del 5\% ( $p<0.05)$. La prevalencia de la familia y las burlas/acoso por el peso entre compañeras fueron de un 38,5\% y un 40,6\%, respectivamente. La insatisfacción corporal se asoció con comportamientos poco saludables de control de peso, cuando estuvo controlada por la familia y las burlas y acoso por el peso entre colegas. Los datos indican que la familia y las burlas/ acoso entre compañeras son aspectos importantes que interfieren en la satisfacción corporal y comportamientos sobre el control de peso.

Conducta Alimentaria; Conducta del Adolescente; Influencia de los Compañeros; Familia
Submitted on $21 / \mathrm{Feb} / 2017$

Final version resubmitted on $06 /$ Oct $/ 2017$

Approved on 31/Oct/2017 